\title{
Misuse of antibiotic among university and higher education students in Sudan a cross-sectional, July 2020.
}

HASSAN HAMED MOHAMMED ALHAJ ( $\square$ haskostex@gmail.com )

Gadarif University https://orcid.org/0000-0003-0860-8443

\section{Alaa Mirgani Babiker Al-lahawi}

Final year medical student, University of Khartoum, Faculty of Medicine,Khartoum, Sudan.

\section{Mohammed Al-abeed}

Final year medical student, University of Khartoum, Faculty of Medicine, Khartoum, Sudan.

\section{Mohammed Eltahier Abdalla Omer}

Gadarif University

\section{Yassir F.Abubakar}

Gadarif regional institute of endemic diseases (GRIED), Gadarif city, Gadarif state, Sudan.

\section{Research Article}

Keywords: Antibiotic misuse, University student, Sudan

Posted Date: June 4th, 2021

DOI: https://doi.org/10.21203/rs.3.rs-590657/v1

License: (c) (1) This work is licensed under a Creative Commons Attribution 4.0 International License. Read Full License 


\section{Abstract}

Background: Misuse of antibiotics therapy refers to failure to end therapy, skipping of doses, re-use of left over. In Sudan, antibiotic resistance is notably high and is attributed to the overuse and misuse of antibiotics. A lot of studies reported improper antibiotic use among university students .

Methods and Materials: A cross-sectional analytical research was done among university and higher education student, using an online-based questionnaire to study misuse of antibiotics and it's relation to different geographical areas in Sudan. The data was analyzed by SPPS version 25.0.

Results: The majority of the participants were female (62\%) and most of them had age more than 20 years. Assessment of antibiotics misuse revealed that many participants don't have adequate behaviour toward antibiotics use. Only $48 \%$ stated that they will visit doctor when feel diseased,37\% of the participants stop taking medication when feel better. Moreover $79 \%$ use antibiotics as prophylaxis.

Comparing antibiotic misuse between type of study groups and parents medical background, those who study a non medical field stop their antibiotic course when feel better more ( $P$ value $<.001)$. taking antibiotic for common cold was more common in students outside medical fields and those whose parents have medical background.

Adjusted regression models showed significant association between using antibiotics without prescription and gender as females use more antibiotics than males 1.6 times. Completing antibiotics course was significantly associated with both type of study and age as medical students and higher age groups practice better.

\section{Conclusion:}

Our study provides a good idea about misuse of antibiotics among universities and higher education students regardless of residency area.

\section{Background}

Misuse of antibiotics therapy refers to failure to end therapy, skipping of doses, re-use of left over. In addition to antibiotics resistance, this behavior also can cause economic loss, increased incidence of treatment failure, and returned visits to the physician. Factors associated with antibiotic therapy misuse included consumer's knowledge and attitude toward antibiotics use for therapy, and physician's knowledge. During a study within the Northeast US, medical students emphasized the necessity for both education and feedback on antibiotics prescribing to control overuse or misuse; which was high among the population in general . Additionally, it had been reported that University students misuse antibiotics. Furthermore, in China, widespread prescribing of unnecessary antibiotics was reported especially those administered parentally.(1) 
In Sudan, self-diagnosis is enhanced by the very fact that most drugs, including antibiotics and antimalarials, can be obtained at community pharmacies without prescription. Although regulations that categorize drugs as prescription only or suitable for over-the-counter sale exist in Sudan, regulatory authorities often lack the resources to enforce them. In Sudan, overall antibiotic resistance is notably high and is attributed to the overuse and misuse of antibiotics. Studies in Sudan showed that $73.9 \%$ and $81.8 \%$ of the general population in Khartoum State had used antibiotics or antimalarials without a prescription and medicines including herbs without medical consultation, respectively. The agents most ordinarily used for self-medication were found to be antibiotics, antimalarials, and analgesics. It was also reported that self-medication was significantly associated with age, income, sex, and level of education. (2)

A lot of studies have reported improper antibiotic use among students both of medical and non-medical colleges with self-medication and adequate lack of knowledge of antibacterial agents (indications, compliance to dosage regimen, specificity of agents to infective organism). While another study concluded that there was a distinct segment between theoretical input and clinical practices, what was being learnt by scholar differs from what was being practiced or they didn't seem to use the theoretical knowledge when it involved real-life situations. A more practical method should be used when educating the students particularly the knowledge of antibiotic use.(3)

Revelation has been set to be the only most noteworthy recorded headway in medical aid. Notwithstanding, the far and wide utilization of antimicrobials has been related with the increase of protection from these specialists. (4) In developing countries most illnesses were treated by selfmedication. Developing countries like Sudan, Jordan, Trinidad and Tobago, and also developed countries like Spain, Greece, Russia, Romania, USA, Italy and Malta are experiencing self medication and irrational use of Antibiotics in their communities.(5) The major influence driving changes within the prevalence of resistance within the community seems to be the quantity of drug use, and different epidemiological models are proposed to explain the phenomena. strategies for better Antibiotics use are important for preserving , as far as possible, the effectiveness of antibiotics. Especially, there's a transparent got to improve the scientific understanding of the factors related to Antibiotics use. So far, most of the efforts for managing the utilization of antibacterial agents are directed toward the prescribers: guidelines, strategies, national and international antibiotics policies, and academic programs.(6)

Our study aim at identifying and estimate the magnitude of antibiotics misuse among university and higher education students in Sudan and provide recommendations if token from being under consideration to real life implementation, the problem will stand no more.

Methods: This was a cross-sectional study design to estimate misuse of antibiotics among university and higher education students in Sudan, We used an online-based questionnaire asking about last time the participants had an illness if they took antibiotics without doctor consultation or despite the doctor instructions they had them anyway, whether or not they discontinue the medication once they feel better , use antibiotics for common cold and as prophylaxis. 
Random sampling method was adopted, all university and higher education students in Sudan whom consented to participate in the study were included, no exclusion criteria was set.

The questionnaire distributed through social media like WhatssApp and Facebook. Participants were encouraged to distribute the survey. Physical distribution was not achievable due to the lockdown in Sudan. The survey was done online by using Google survey (Google LLC, Mountain View, California, USA).

Ethical statement : written informed consent have been provided from the study participents and all data were fully anonymized hence ethics committee approval has been waived.

\section{Results}

This online cross-sectional study included 725 students from all over Sudan. The majority of the participants were female (62\%) and most of them had age more than 20 years old. About $90 \%$ were university students and the rest were studying post graduate studies. Three quarters of the study participants are studying in medicine related fields. Up to $35 \%$ of participant's parents have medical background. More details about demographic characteristics are included in table 1.

Table 1: Basic demographic features

\begin{tabular}{|l|c|}
\hline Gender: (\%) & 38.1 \\
Males & 61.9 \\
Females & \\
\hline Age: (\%) & 30.3 \\
Less than 20 & 69.7 \\
More than 20 & \\
\hline Education: (\%) & 90.3 \\
Undergraduate & 9.7 \\
Postgraduate & 75 \\
\hline Study participants: (\%) & 25 \\
Medical & \\
Non medical & 3.4 \\
\hline Residency: (\%) & 35.3 \\
Northern states & 55.9 \\
Eastern states & 5.5 \\
Central states & \\
Western states & 12.1 \\
\hline Parents' education: (\%) & 31.2 \\
Primary & 56.7 \\
Secondary & 35 \\
\hline Graduate education and above & \\
\hline parents medical background:(\%) & \\
\hline Monthly income: (\%) & 41.5 \\
15000 or less & 58.5 \\
\hline More than 15000
\end{tabular}


Assessment of antibiotics misuse revealed that many participants didn't have definite behaviour toward antibiotics use. Only $48 \%$ of participants stated that they will visit doctor when feel diseased. Also $37 \%$ of the participants stopped taking medication when felt better. Moreover, $79 \%$ of them used antibiotics as prophylaxis. More details in table 2.

Table 2: features of antibiotics use among participants.

\begin{tabular}{|l|l|}
\hline What did you do last time you had a disease? (\%) & 34.7 \\
Used antibiotics & 17.6 \\
Did nothing & 47.7 \\
Visited a doctor & \\
\hline If you visited a doctor, what did you do then: (\%) & 28.7 \\
Had antibiotic although the doctor did not prescribe & 71.3 \\
\hline The doctor prescribed me antibiotics & \\
\hline When you start taking antibiotics, the following is true : (\%) & 36.8 \\
Stop taking the drug when feeling better & 63.2 \\
\hline Complete the course of antibiotics & \\
\hline From where do you get antibiotics: (\%) & 23.4 \\
I use old remaining stock & 76.6 \\
I buy them from pharmacy & \\
\hline Do you take antibiotics when you feel common cold symptoms: (\%) & 21.1 \\
Yes & 78.9 \\
No & \\
\hline Do you use antibiotics for prophylaxis: (\%) & 78.9 \\
Yes & 21.1 \\
\hline No
\end{tabular}

When comparing antibiotic misuse between types of study groups and Parents' medical background, those who have studied a non-medical field stop their antibiotic course when feel better more than those who have studied a medical field ( $P$ value <.001). Moreover, taking antibiotic for common cold was more common in students outside medical field and those whose Parents have medical background. Details in table 3.

Table 3: comparison of antibiotic misuse between medical field and non medical field students, and Parent's medical background. 


\begin{tabular}{|c|c|c|c|c|c|c|}
\hline & \multicolumn{3}{|c|}{ Study participants } & \multicolumn{3}{|c|}{$\begin{array}{c}\text { Parents' medical } \\
\text { background }\end{array}$} \\
\hline & Medical & $\begin{array}{l}\text { Non } \\
\text { medical }\end{array}$ & P value & Medical & $\begin{array}{l}\text { Non } \\
\text { medical }\end{array}$ & $\begin{array}{l}P \\
\text { value }\end{array}$ \\
\hline $\begin{array}{l}\text { Having antibiotic without } \\
\text { prescription }\end{array}$ & $\begin{array}{l}162 \\
(32.9 \%)\end{array}$ & $\begin{array}{l}65 \\
(40.1 \%)\end{array}$ & 0.154 & $\begin{array}{l}78 \\
(34.6 \%)\end{array}$ & $\begin{array}{l}149 \\
(34.7 \%)\end{array}$ & 0.949 \\
\hline $\begin{array}{l}\text { Stop antibiotics course when } \\
\text { feeling better }\end{array}$ & $\begin{array}{l}109 \\
(31.5 \%)\end{array}$ & $\begin{array}{l}58 \\
(53.2 \%)\end{array}$ & $<0.001$ & $\begin{array}{l}56 \\
(34.5 \%)\end{array}$ & $\begin{array}{l}111 \\
(38 \%)\end{array}$ & 0.466 \\
\hline $\begin{array}{l}\text { Getting new medications from } \\
\text { pharmacy }\end{array}$ & $\begin{array}{l}233 \\
(77.6 \%)\end{array}$ & $\begin{array}{l}87 \\
(73.7 \%)\end{array}$ & 0.392 & $\begin{array}{l}108 \\
(73.4 \%)\end{array}$ & $\begin{array}{l}212 \\
(78.2 \%)\end{array}$ & 0.273 \\
\hline $\begin{array}{c}\text { Taking medication for common } \\
\text { cold symptoms }\end{array}$ & $\begin{array}{l}260 \\
(47.8 \%)\end{array}$ & $\begin{array}{l}106 \\
(58.6 \%) \\
\end{array}$ & 0.012 & $\begin{array}{l}142 \\
(55.9 \%)\end{array}$ & $\begin{array}{l}224 \\
(47.6 \%)\end{array}$ & 0.032 \\
\hline Using antibiotics as prophylaxis & $\begin{array}{l}92 \\
(16.9 \%)\end{array}$ & $\begin{array}{l}61 \\
(33.7 \%)\end{array}$ & $<0.001$ & $\begin{array}{l}67 \\
(26.4 \%)\end{array}$ & $\begin{array}{l}86 \\
(18.3 \%)\end{array}$ & 0.011 \\
\hline
\end{tabular}

East state residents showed higher tendency to take medication for common cold and use antibiotics as prophylaxis than those of middle states residents, details in table 4.

ble 4 : comparison of antibiotic misuse between different States .

\begin{tabular}{|c|l|l|l|l|l}
\hline \multirow{2}{*}{\begin{tabular}{l} 
Central states \\
\cline { 2 - 6 }
\end{tabular}} & $\begin{array}{l}\text { North } \\
\text { states } \\
\text { states }\end{array}$ & $\begin{array}{l}\text { East } \\
\text { states }\end{array}$ & $\begin{array}{l}\mathbf{P} \\
\text { value }\end{array}$ \\
\hline $\begin{array}{c}\text { Having antibiotic without } \\
\text { prescription }\end{array}$ & $5(22 \%)$ & $82(35 \%)$ & $(36 \%)$ & $\begin{array}{l}9 \\
(27 \%)\end{array}$ & $\mathbf{0 . 1 1 4}$ \\
\hline $\begin{array}{c}\text { Stop antibiotics course when feeling } \\
\text { better }\end{array}$ & $7(43 \%)$ & $68(40 \%)$ & $81(34 \%)$ & $\begin{array}{l}9 / \\
(45 \%)\end{array}$ & $\mathbf{0 . 4 9}$ \\
\hline $\begin{array}{c}\text { Getting new medications from } \\
\text { pharmacy }\end{array}$ & $5(38 \%)$ & $36(32 \%)$ & $49(21 \%)$ & $\begin{array}{l}6 / \\
(37 \%)\end{array}$ & $\mathbf{0 . 2 1 1}$ \\
\hline $\begin{array}{c}\text { Taking medication for common cold } \\
\text { symptoms }\end{array}$ & $12 /$ & $\begin{array}{l}147 / \\
(58 \%)\end{array}$ & $\begin{array}{l}218 / \\
(55 \%)\end{array}$ & $\begin{array}{l}21 / \\
(53 \%)\end{array}$ & $\mathbf{0 . 0 1 4}$ \\
\hline $\begin{array}{c}(50 \%) \\
\text { Using antibiotics as prophylaxis }\end{array}$ & $3 /(12 \%)$ & $68 /(27 \%)$ & $74 /(18.5 \%)$ & $\begin{array}{l}5 / \\
(13 \%)\end{array}$ & $\mathbf{0 . 0 2 3}$ \\
\hline
\end{tabular}

Adjusted regression models showed significant association between using antibiotics without prescription and gender, as females use more antibiotics than males 1.6 times. Completing antibiotics course was significantly associated with both type of study and age as medical students and higher age group practice better. Getting medication from the pharmacy was associated with gender, as female use new pharmacy medications more than males. While completing the antibiotics course was associated with type of studies and age as medical studies and higher age are associated with more completing of the antibiotic course. Details in table 5 and table 6.

Table 5: Adjusted regression model for antibiotic use, following doctor medications and completing antibiotic course. 


\begin{tabular}{|c|c|c|c|c|c|c|}
\hline & \multicolumn{2}{|c|}{$\begin{array}{c}\text { Using antibiotics } \\
\text { without prescription }\end{array}$} & \multicolumn{2}{c|}{$\begin{array}{c}\text { Followingdoctors' } \\
\text { medications }\end{array}$} & \multicolumn{2}{c|}{$\begin{array}{c}\text { Completing } \\
\text { antibiotics course }\end{array}$} \\
\cline { 2 - 7 } & Odds ratio & P value & Odds ratio & P value & $\begin{array}{c}\text { Odds } \\
\text { ratio }\end{array}$ & P value \\
\hline Gender & 1.6 & 0.012 & 1.5 & 0.089 & 1 & 0.994 \\
\hline Age & 1.05 & 0.772 & 1.13 & 0.638 & 1.99 & 0.002 \\
\hline Study participants & 1.19 & 0.395 & 1.16 & 0.563 & 2.57 & $<0.001$ \\
\hline $\begin{array}{c}\text { Parent's medical } \\
\text { background () }\end{array}$ & .97 & 0.868 & 1.39 & 0.194 & 1.08 & 0.709 \\
\hline Income & .98 & 0.909 & 1.43 & 0.129 & 1.39 & 0.101 \\
\hline
\end{tabular}

Table 6: adjusted regression for getting medications from pharmacy, use antibiotics for common cold and using antibiotics as prophylaxis.

\begin{tabular}{|c|l|l|l|l|l|l|}
\hline \multirow{2}{*}{} & \multicolumn{2}{|c|}{$\begin{array}{l}\text { Getting new medications } \\
\text { from the pharmacy }\end{array}$} & \multicolumn{2}{c|}{$\begin{array}{c}\text { Use antibiotics for } \\
\text { common cold symptoms }\end{array}$} & \multicolumn{2}{c|}{$\begin{array}{l}\text { Using antibiotics } \\
\text { for prophylaxis }\end{array}$} \\
\cline { 2 - 7 } & Odds ratio & P value & Odds ratio & P value & $\begin{array}{l}\text { Odds } \\
\text { ratio }\end{array}$ & P value \\
\hline Gender & .548 & 0.022 & 1.1 & 0.616 & .638 & 0.024 \\
\hline Age & 1.83 & 0.016 & .739 & 0.072 & .634 & 0.025 \\
\hline Type of study & 1.6 & 0.086 & .619 & 0.009 & .404 & $<0.001$ \\
\hline $\begin{array}{l}\text { Parents' medical } \\
\text { background }\end{array}$ & .784 & 0.332 & 1.5 & 0.014 & 1.89 & 0.001 \\
\hline Income & 1.15 & 0.546 & .593 & 0.001 & .687 & 0.048 \\
\hline
\end{tabular}

\section{Discussion}

Self-medication with antibiotics is common among students of medical and non-medical disciplines.

In Sudan, the prevalence of self-medication with antibiotics among undergraduate students in Khartoum State is high.(2)

Results of another Sudanese study showed that

the prevalence of self-medication with antibiotics during the 6 month prior to the study was $41 \%$, so this is confirming that self-medication with antibiotics is a frequent problem in Sudan and thus interventions are urgently required to reduce the frequency of antibiotics misuse.(5)

Worldwide, misuse of antibiotic is one of the most important challenges to health care system, because reduction of antibiotic resistance is achieved by controlled use of antibiotics.(1) This is a major health problem that emphasize the urgent need of adding some courses on rational antibiotic use in University curricula.(7)

In this online cross-sectional study,725 students from all over Sudan were included, three quarters of our study participants were studying medicine-related fields. Up to $35 \%$ of participants' parents have medical background and this may contribute to antibiotics misuse in a way of skipping doctor visit and go directly 
to direct antibiotics consumption. In contrast, in a Chinese study most of students' parents had limited or no college education and with no medical background.(8)

Assessment of antibiotics misuse revealed that many participants didn't have adequate behavior toward antibiotics use may be due to decreased awareness about the adverse effects of unnecessary antibiotic use. Similar to Chinese study that showed medical students have high rates of antibiotic self-medication for self-limiting illnesses, symptom relief and prophylaxis; and this might be higher than the reported number since they may not report these behaviors because they were medical students and know this is inappropriate .

In our study eastern and middle states have comparably high level of antibiotic misuse unlike the Chinese study which showed that the less developed region(Guizhou Province) was significantly associated with higher antibiotic misuse behaviors.(9)

In Nigeria, there was good theoretical knowledge of antibiotic use and resistance, however, practice levels were poor since only $8.2 \%$ of respondents always consulted a doctor before starting an antibiotic.(4)

Similarly, in a study conducted in Sudan during 2019, participants had shown $44.44 \%, 34.3 \%, 20.3 \%$ and $1 \%$ good, poor, very good and excellent knowledge on resistance, respectively. About $34.3 \%$ of respondents have poor knowledge which was a huge number. However, only $24.8 \%$ of them had a good attitude; thus the attitude was average, which is not enough in a population of students who are studying health related fields and having good knowledge.(3)

In another Sudanese study, surprisingly despite respondents higher level of education, the majority of those who practiced self medication with antibiotics were university graduates and university students.(5)

In United Arab Emirates, medical students scored remarkably better than non-medical students on KAP of antibiotic use.(7)

In Saudi study, $67 \%$ of the respondents were unaware of the meaning of ABs resistance. $24 \%$ believed that $A B$ s worked on viruses, $31 \%$ on cold and $21 \%$ can cure cough. Only $33 \%$ of them understand the meaning of $A B$ s resistance, $45.8 \%$ agreed that $A B s$ resistance is caused by using unwarranted $A B s$, and $55.4 \%$ agreed that it caused by incomplete course of $A b s$. (6)

Only $48 \%$ of our participants stated that they will visit a doctor when feel diseased. In a study done in Jordan, $61.4 \%$ of the medical students reported that they had seen physicians at least 1 time in the past 6 months from the time of the study, which was comparable to that of the nonmedical students $(68.6 \%)$ and cold was one of the major reasons for visiting physicians among Jordan participants (26.4\%). Both groups of students reported that they highly adhered to doctor instruction.(1)

In Chinese study.. 29\% medical students reported at least one self-limiting illness in the prior month of the study time. Of those, $21 \%$ went to see a doctor, of which $58 \%$ were prescribed antibiotics . Of the students 
reporting illness of cold, $16.8 \%$ only went to see a doctor.(8)

$37 \%$ of our participants stop taking medication when they feel better. When comparing antibiotic misuse between types of our study groups.. those who study a non medical field stop their antibiotic course when feel better more than those who study a medical field ( $P$ value $<.001)$. While the majority of Jordan participants (65.3\%) reported that they stopped using the medicine and saw physicians whenever the drug had no effect. Another study done in south Jordan revealed that half the participants used the antibiotic for three days or less depending mainly on the symptoms. In study done in Nigeria, $41 \%$ of their respondents never stopped taking their antibiotics when they felt better, $36.6 \%$ sometimes and $13.1 \%$ usually stopped taking their antibiotics when they felt better..(4)

In Sudanese study during 2006, when a noticeable improvement in the illness occurred during selftreatment, respondents reported continuing treatment until the medication was gone is $71.8 \%$ which is a good percentage. Those who stopping treatment immediately after experiencing noticeable improvement were $28.2 \%$.(2)

Another Sudanese study showed that the majority of those who self-medicated used antibiotics for a short duration of less than 5 days. (5)

In Saudi study, $58 \%$ respondents discontinued using ABs after completing the course while $42 \%$ discontinue $A B s$ on alleviation of symptoms. (6)

In our study, $79 \%$ use antibiotics as prophylaxis and this is common among non medical ( $p$ value < 0.001 ) and $21 \%$ take antibiotics when they feel common cold symptoms. In study done in Sudan, $41 \%$ of those who self-medicated used antibiotics to treat cough and common colds.(5)

In china, of the students reporting illness of cold, $59.2 \%$ of them were self-medicated and one in seven participants used antibiotics for preventing a cold.(8)

In Saudi, almost $51 \%$ used ABs without physician prescription.(6)

In Jordan, the most predominant medicine classes that were self-used by all students in the past 6 months were variable and the antibiotics used by

$21 \%$ of the participants.(1)

Moreover, taking antibiotics for the common cold was more common in our students outside medical fields similar to Jordan study where cold was an indication for which students take medications on their own with percent of $58.3 \%$.(1)

In our study, taking antibiotics for common cold common among those whose parents work in the medical fields. This is inappropriate but may be that working in medical fields not nessecitae good knowledge and good delivery of right information to the families. In china, Logistical regression showed that students whose fathers had a higher education level, whose mothers had medical background, were more likely to stock antibiotics and self-medicate with antibiotics.(8) 
Adjusted regression models in our study showed significant association between using antibiotics without prescription and gender as females use more antibiotics than males 1.6 times. In Chinese study, female students had significantly higher rates of stocking antibiotics.(8)

In Nigeria, more male respondents had a better knowledge of antimicrobial use and resistance than their female counterparts $(70.4 \%$ vs. $55.1 \%$; $P=0.035)$ and this is statistically significant.(4) In Sudanese study, self-medication was slightly higher among females.(5) This is related to our finding that getting medication from the pharmacy was associated with gender as female use new pharmacy medications more than males.

In our study, completing antibiotics course was significantly associated with both type of study and age. So medical students do the right practice of completing the antibiotic course more than the non medicals, also higher age group practice better. In contrast, older age students in Chinese study had significantly higher rates of stocking antibiotics.(8)

In study done in Sudan 2006, self medication with any of the antibiotics and/or antimalarials was shown to be significantly associated with age group $(p=0.008)$.(2) Another Sudanese study showed that the prevalence of self-medication was found to be inversely proportional to age. It was highest among those aged between 18 to 24 years.(5)

None of the variables such as gender, age, and education level showed statistical significance when compared with knowledge response regarding AB resistance in Saudi study. (6)

similarly, In study done in Sudan2019, students characteristics like age, gender have negligible impact on the students knowledge and attitude.(3)

\section{limitations :}

1/ physical distribution of questionnaire wasn't achievable due to Covid-19 lockdown. distribution of questionnaire in western and northern states was suboptimal, we think in addition to the lack of physical distribution, the number of universities is less compared to eastern and middle states .

\section{Recommendations}

1/it is critical to raise awareness about Abs misuse and AMR specially in non medical students.

2/Regulations and policies regarding Abs sale should be formulated and/or implicated.

\section{Declarations}

Author's Contribution: All authors participated in the manuscript editing and preparation. AMB/MEA were responsible for draft writing, conceiving the idea for the article and wrote the final manuscript. MA 
analyzed the data of this study and participated in draft writing. All authors contributed to and approved the final report.

Declaration of Competing Interest: The authors declare no conflict of interest.

\section{References}

1. / Alshogran, O., Alzoubi, K., Khabour, O. and Farah, S., 2018. Patterns of self-medication among medical and nonmedical University students in Jordan. Risk Management and Healthcare Policy, Volume 11, pp.169-176.

2. /Awad, A. and Eltayeb, I., 2007. Self-Medication Practices with Antibiotics and Antimalarials Among Sudanese Undergraduate University Students. Annals of Pharmacotherapy, 41(7-8), pp.1249-1255.

3. /Sa'adatu Sunusi, L., Mohamed Awad, M., Makinga Hassan, N. and Abubakar Isa, C., 2019. Assessment of Knowledge and Attitude toward Antibiotic Use and Resistance among Students of International University of Africa, Medical complex, Sudan. Global Drugs and Therapeutics, 4(2).

4. /Alex, I., 2019. Knowledge of antibiotic use and resistance among students of a medical school in Nigeria. Malawi Medical Journal, 31(2), p.133.

5. /A.ELHADI, A. and B.Eltayeb, I., 2014. PATTERN OF SELF-MEDICATION WITH ANTIBIOTICS IN KHARTOUM STATE, SUDAN. World Journal of Pharmaceutical Research,.

6. /Al-Shibani, N., Hamed, A., Labban, N., Al-Kattan, R., Al-Otaibi, H. and Alfadda, S., 2017. Knowledge, attitude and practice of antibiotic use and misuse among adults in Riyadh, Saudi Arabia. Saudi Medical Journal, 38(10), pp.1038-1044.

7. /Jairoun, A., Hassan, N., Ali, A., Jairoun, O. and Shahwan, M., 2019. Knowledge, attitude and practice of antibiotic use among university students: a cross sectional study in UAE. BMC Public Health, 19(1).

8. /Hu, Y., Wang, X., Tucker, J., Little, P., Moore, M., Fukuda, K. and Zhou, X., 2018. Knowledge, Attitude, and Practice with Respect to Antibiotic Use among Chinese Medical Students: A Multicentre CrossSectional Study. International Journal of Environmental Research and Public Health, 15(6), p.1165.

9. /Peng, D., Wang, X., Xu, Y., Sun, C. and Zhou, X., 2018. Antibiotic misuse among university students in developed and less developed regions of China: a cross-sectional survey. Global Health Action, 11(1), p.1496973. 